\title{
Optimization of Support Structures for Offshore Wind Turbines Using Genetic Algorithm with Domain-Trimming
}

\author{
Mohammad AlHamaydeh,, Samer Barakat, ${ }^{2}$ and Omar Nasif ${ }^{2}$ \\ ${ }^{1}$ Department of Civil Engineering, American University of Sharjah, Sharjah, UAE \\ ${ }^{2}$ Department of Civil Engineering, University of Sharjah, Sharjah, UAE \\ Correspondence should be addressed to Mohammad AlHamaydeh; malhamaydeh@aus.edu
}

Received 18 December 2016; Revised 5 April 2017; Accepted 10 May 2017; Published 8 August 2017

Academic Editor: Filippo Ubertini

Copyright ( 2017 Mohammad AlHamaydeh et al. This is an open access article distributed under the Creative Commons Attribution License, which permits unrestricted use, distribution, and reproduction in any medium, provided the original work is properly cited.

\begin{abstract}
The powerful genetic algorithm optimization technique is augmented with an innovative "domain-trimming" modification. The resulting adaptive, high-performance technique is called Genetic Algorithm with Domain-Trimming (GADT). As a proof of concept, the GADT is applied to a widely used benchmark problem. The 10-dimensional truss optimization benchmark problem has well documented global and local minima. The GADT is shown to outperform several published solutions. Subsequently, the GADT is deployed onto three-dimensional structural design optimization for offshore wind turbine supporting structures. The design problem involves complex least-weight topology as well as member size optimizations. The GADT is applied to two popular design alternatives: tripod and quadropod jackets. The two versions of the optimization problem are nonlinearly constrained where the objective function is the material weight of the supporting truss. The considered design variables are the truss members end node coordinates, as well as the cross-sectional areas of the truss members, whereas the constraints are the maximum stresses in members and the maximum displacements of the nodes. These constraints are managed via dynamically modified, nonstationary penalty functions. The structures are subject to gravity, wind, wave, and earthquake loading conditions. The results show that the GADT method is superior in finding best discovered optimal solutions.
\end{abstract}

\section{Introduction and Background}

Offshore structures offer presumably the greatest level of sophistication and difficulty in the analysis, design, and construction stages. This is due to multitude of complexities introduced by the offshore locations. The entailed unique conditions such as underwater currents, surface waves and wind, and seabed soil can often become problematic quickly. Such conditions introduce additional factors to the design challenge, such as extreme temperatures and rough weather conditions, marine growth, fatigue, corrosion, marine vessel impact, and interaction with aeroelastic and hydrodynamic loads. These conditions need to be thoughtfully taken into consideration due to the long and short term effects that can compromise the structure. The intricacy of the design and analysis process multiplies when earthquake loads are factored in. However, it is recommended to account for all loads simultaneously except for seismic loads, based on the potential occurrence combinations $[1,2]$. Therefore, seismic effects are not typically considered to occur at the same time as other loads [3]. The considered combinations of different loads and their influence on the design of offshore structures are further elaborated on in a later section.

The design solution selected from a range of viable options often imposes additional restraints to the structural design as it shapes the structure's response to the applied loads. The size, type, and configuration of the members supporting offshore structure, for instance, may produce a significant influence on marine growth size, which poses a consequent impact on hydrodynamic drag forces. The resulting effects of nonlinearities associated with fluid-structure interaction may be too significant for a thoughtless dismissal in the design phase [4]. Furthermore, the interaction between the soil, foundation, and the structure is crucial phenomenon to be studied for the development of enhanced structural system designs supporting offshore wind towers [5-10]. 
A common simplified approach to the complex process of offshore structural design is the use of uncoupled load effects [11-13]. The justification of the above simplified method in fatigue analysis is attributable to the following: (a) material and geometric nonlinearities are not significant structural fatigue responses, (b) wind and wind-induced currents and waves can be assumed as stationary and independent processes, and (c) soil stress levels are moderate to presume linear behavior under wind and sea wave loading [14]. Employing such approach allows for the advantageous implementation of simple soil-structure interaction behavior.

Devising optimal designs that satisfy multiple performance criteria, such as minimizing cost and maximizing efficiency, is arguably one of the most influential factors in modern structural design. Member-level (local) optimization techniques are routinely used to identify design quantities for acceptable structural performance. Within this framework, several optimization techniques have been utilized in the past [15]. In the presence of multiple optima and nonsmooth constraints in the design variable space, it is difficult to obtain a set of optimum values using member-level optimization formulations. This shortcoming inspired researchers to explore using the relatively new and innovative evolutionarybased optimization techniques. For example, these methods have been used recently to address structural engineering optimization problems: Shuffled Complex Evolution Optimizer (SCEO), Ant Colony Optimization (ACO), the Genetic Algorithms (GA), and Particle Swarm Optimizer (PSO) (e.g., [16-24]).

Many structural optimization problems involve problemspecific constraints applicable to the solutions limiting the feasible search space. In these types of problems, it is challenging to adapt traditional optimization techniques to handle constraints. One of the most popular constraint handling methods is by incorporating penalty functions due to the relative simplicity and ease of implementation.

Topology optimization was used by many researchers to generate alternative structural design concepts for benchmark wind turbine blades. In these studies, the focus is alternative structural layout for wind turbine blades with the aim of improving its design, minimizing weight, and, ultimately, wind energy cost reduction (e.g., [25-35]).

The materials' cost for offshore wind turbine supporting structures constitutes a considerable amount of overall cost. Potentially significant cost savings that result from optimized structural designs encourage the incorporation of efficient optimization techniques. However, determining the optimal structural shape and weight of the supporting system is not a trivial task. The complexity is increased due to the mathematical description of loads (aeroelastic [wind], hydrodynamic, and seismic), the many variables describing the geometry, the nonsmooth objective function, and the constraints that have to be satisfied. The above considerations have inspired the implementation of the efficient Genetic Algorithm with Domain-Trimming (GADT) optimization technique.

This study presents the implementation of the GADT to achieve superior optimization. The capabilities of the presented optimization tool are demonstrated on a well-established optimization benchmark problem known for being challenging with known global and multiple local minima. Finally, the GADT tool is used to solve two typical leastweight design problems for offshore wind turbine supporting structures through topology and member size optimization. The algorithm is coded using the MATLAB [36] commercial software package and its GA libraries, while the structural analysis and design for the different topology and loading configurations is performed using the SAP2000 [37] commercial software package. The linkage and automation of the structural analysis and design tasks are initiated from within the MATLAB code and established through the Open Application Programming Interface (OAPI) capabilities of the SAP2000 software.

\section{Primary Loads on Offshore Structures}

2.1. Hydrodynamic Loads (Sea Waves and Currents). Hydrodynamics [the kinematics of the water particles] is a very sophisticated branch of applied science that has been studied extensively. The motion of salty ocean water is a result of several causes, such as tidal effects that initiate underwater currents, thermal gradient effects, surface-level winds, and topology of the seabed especially for shallow waters (where the water depth is lesser than half the characteristic wavelength). All of the mentioned which are site dependent and their individual influences and their interactions would potentially vary significantly.

Several wave theories exist which span in sophistication and acceptance. Among the widely used theories are the following: linear or Airy wave theory, Stokes 2nd-order and higher order theories, and stream-function and cnoidal wave theories $[44,45]$. The range of applicability of the different wave theories can be found in [4]. The superposition of several Airy wavelets is routinely used to model the irregular sea states. The specifics of the site conditions can be captured through the different wavelength, amplitude, phase, and direction of the superimposed linear waves $[4,46]$.

When wave loading is applied to an offshore structure, by means of Airy's wave theory and Morison's equation, gravity loads are assumed to be simultaneous. The analysis often accounts for the various nonlinearities introduced by the nonlinear hydrodynamic force (drag and lift). Typical representation of wave loads is based on the three parameters: wave period, wave height, and mean water depth (Figure 1(a)). The velocity along the water depth is assigned a nonlinear profile to account for the appropriate experimentally observed conditions, as can be seen in Figure 1(b). Drag and inertial force profiles are also representative of realistic situations. Figure 1(c) schematically depicts the different wave and current actions and effects on an offshore pole with a circular cross-section of diameter $(D)$.

In such mathematical procedures, wave and current kinematic fields are often modeled using 5th-order Stokes wave theory. Forces on individual structural elements are then generated using Morison's equation. These forces account for the inertial effects through the mass coefficient $C_{m}$ and the hydrodynamic drag via the coefficients $C_{d}$ [47]. The used values for this research are adopted from the American 


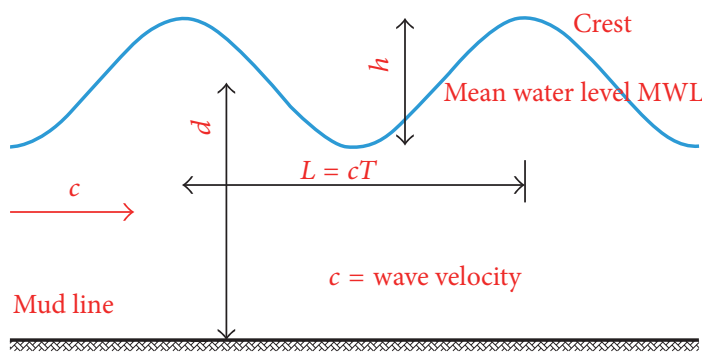

(a)

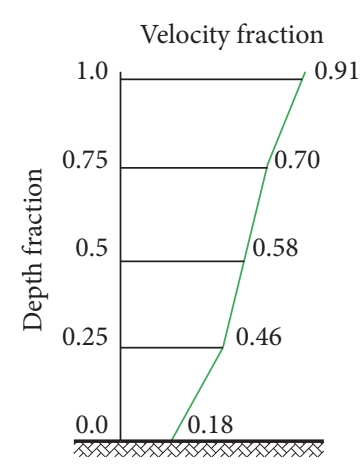

(b)

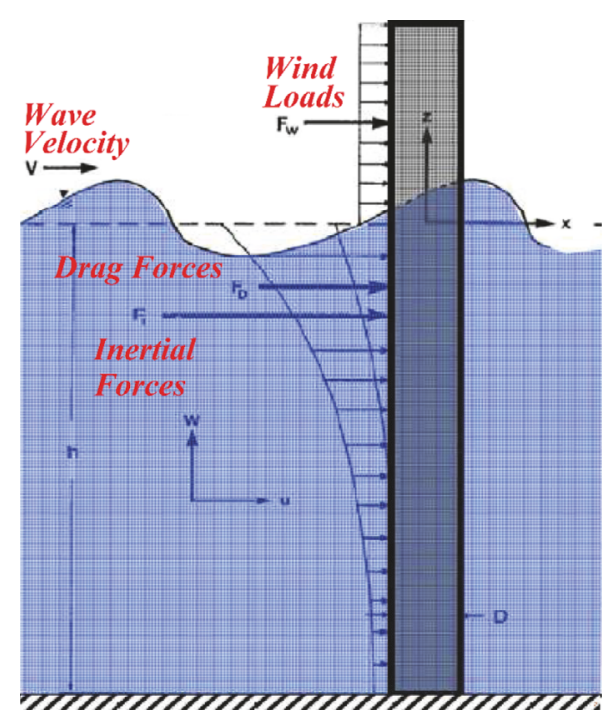

(c)

FIGURE 1: Schematic representation of offshore loads (a) sea current wave profile (adopted from [47]); (b) velocity profile (adopted from [47]); (c) hydrodynamic loads (adopted from [48]).

Petroleum Institute (API) standards $[1,2]$ and will be introduced in Section 4.1.

Specifics and more details of quantifying such forces can be found elsewhere [4, 47-49]. Although the forces induced by ocean waves on platform are dynamic in nature, it is the common practice to design by static approaches. This is deemed a reasonable approximation especially for rigid offshore structures submerged in shallow to intermediate water levels. As the water depth increases and/or offshore structures become more compliant (flexible), the dynamic effects gain significance. In such cases, static loading conditions assumption will no longer be appropriate.

2.2. Current Loads. Waves induce orbital particle motion through the matter in which they travel; such orbits are typically closed but may undergo minor forward drift resulting from wind-surface interaction effects. So, in essence, currents are produced due to wave kinetic energy. If a current coincides with a wave propagation path or direction, the wave length is typically elongated $[1,48]$.

2.3. Wind Loads. Atmospheric temperature and pressure gradients provide wind with ample kinetic energy. As obstacles are placed in the path of this kinetic energy, some or all of it is converted into potential energy due to path deflection or obstruction and discontinuation. The generated potential energy is manifested through differential pressures on the obstacle body. The resulting pressures are influenced by many factors such as the obstacle shape, orientation in space, and contact area, as well as the wind speed and angle of approach. Wind-induced forces are highly dynamic in nature, but often times, for design purposes, it is deemed appropriate to represent them by equivalent static pressures.
Land-based structures approaches can be adopted for representing wind loads on offshore structures with proper adjustments accounting for open ocean surface roughness (lower category of surface roughness). The lesser roughness produces lower levels of turbulence than would be produced on land; this is translated into a slower rate of variation with height. That is, at any given height, the storm conditions are more severe and produce higher wind speeds in offshore locations as compared to onshore. An illustrative schematic is provided in Figure 2.

2.4. Earthquake Loads. As the ground shakes under a structure during a seismic event, inertial forces are generated within the structure. During that oscillatory vibrational movement, other forces are engaged as well, namely, dissipative forces (damping) and restoring forces. The interaction between all these forces to maintain dynamic equilibrium gives rise to complex structural response. Being an extreme event, seismic activity often involves high structural response demands where inelastic and nonlinear response is to be expected, thus adding to the already complex interactive loading situation in an offshore site. Luckily, significant seismic events are not very frequent and require relatively a long time to build up (store) strain energy. This warrants separate (nonsimultaneous) consideration of earthquake loads from other loads for offshore structures. At offshore sites, tidal waves may or may not require special attention depending on the specific site conditions. Tidal waves travel with great velocities at sea but with small amplitude (wave height) as large bodies of water are displaced during an earthquake. It is only as these waves approach the shoreline that they attain huge amplitudes due to the shallow depths of the seabed. These scenarios are considered on site-specific basis and require special seismic hazard studies prior to any design 


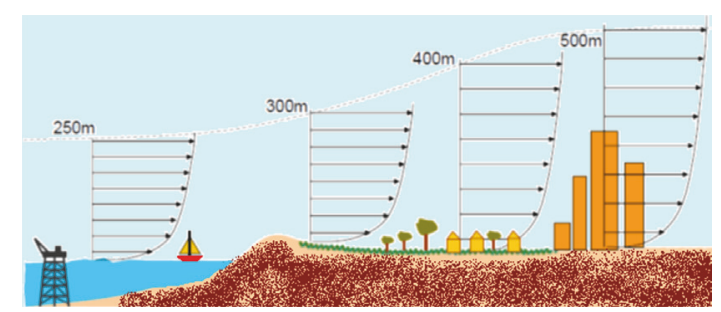

FIgURE 2: Variation of mean wind speed with height (adopted from [4]).

efforts. The authors are not aware of any specific tidal wave design codes for offshore structures.

When seismic loads are deemed significant to control the offshore structural design either partially or entirely, equivalent static representations are often utilized. This is very much similar to design considerations of on-land sites. If the offshore structure under consideration is irregular or complex in geometry, dynamic (linear or otherwise nonlinear) response needs to be properly modeled. The details of the used design code, design loads, design load combinations, and so forth are specified in Section 4.1 where a numerical example is introduced.

\section{Genetic Algorithm with Domain-Trimming (GADT)}

3.1. Development of the GADT Optimization Technique. In the master's thesis of the third author [50], the GADT optimization algorithm was introduced by augmenting the GA with a domain-trimming (DT) to enhance its capacity of discovering global optima. Conventional GA optimization begins with a randomly generated population of solution alternatives $N_{p}$ (population size) using a uniform probability distribution; a combination of variables $\left(x_{1}, x_{2}, x_{3}, \ldots, x_{n}\right)$ comprises each solution of the GA having its own fitness value. When the optimization is performed to find the least weight for a given problem, a function $F^{*}{ }_{j}(\mathbf{X})=$ total mass + penalty must be minimized. Low $F^{*}{ }_{j}(\mathbf{X})$ yielding solution alternatives would have better fitness while they maintain the problem constraints satisfied. A fitness value is allocated to each solution $j$ using (1) once $F^{*}{ }_{j}(\mathbf{X})$ is computed for all the solutions in the initial population. Solutions with $F^{*}{ }_{j}(\mathbf{X})$ higher than the population's $F^{*}$ ave are eliminated by an assigned fitness value of zero as they are deemed unfit:

$$
F_{j}(\mathbf{X})=\left\{\begin{aligned}
0 & \text { for } F^{*}{ }_{j}(\mathbf{X}) \geq F^{*} \text { ave } \\
F^{*} \text { ave }-F^{*}{ }_{j}(\mathbf{X}) & \text { for } F^{*}{ }_{j}(\mathbf{X})<F^{*} \text { ave } \\
j & =1,2, \ldots, N_{p},
\end{aligned}\right.
$$

where $(\mathbf{X})$ is the design variables vector.

The three basic operations of a GA-reproduction, crossover, and mutation-are the tools improving each population's fitness across generations/iterations. During reproduction, better fit designs are selected, copied, and placed into a pool allowing each design to mate and reproduce. The selection method used in this study is the roulette wheel due to its simplicity and popularity. One prominent advantage of the GA optimization is its inherent resilience against converging to local optima rather than global optima. GA's resilience can also be sometimes a potential shortcoming as its "low-resolution" becomes problematic. This is especially prominent when the population size is relatively limited. In such cases, the technique may converge to solutions that are in the vicinity of, but not necessarily at, the global minima. An explanation to such occurrence is that solution variables are first randomly selected from a predetermined domain, which do not change in nature but rather in location from one solution to the other, except for mutation, which occurs at small probability. Such issue is aggravated by poor choices of solution domains, for example, selecting a domain of [1, 1000] while the optimal is at a value of 2 . While blending techniques aim at reducing this drawback, they may pose a distinct undesirable effect of refuting the strong traits of the parents.

This study features a new technique developed to tackle GA's limitation, which involves first reducing the selected domain and then recommencing the GA algorithm to enhance the probability of selecting the optimal solution. To demonstrate, take the previous example of an optimum solution of 2 which is searched for in a domain of $[1,1000]$. When the same solution is searched for in a "trimmed" domain of $[1,10]$, the probability of being selected as the optimal solution is increased 200-fold, when the GA is reinitiated and all else maintained constant. Domain-trimming is carried out herein by reducing a percentage $(10 \%)$ of the initial domain. A continuity of domain reduction and reinitiation is maintained until the global optimum solution is located.

Naturally, the possibility that the global optima may exist within the removed (trimmed) region of the solution space persists. In such cases, the GADT will converge to equivalent solution achieved by the typical GA algorithm, as trimming is queued only by the initial convergence of the GA process. Experimentation has demonstrated that the GADT technique will typically outperform conventional GA as will be shown herein with the offshore support structure examples.

3.2. Constraints Handling. Penalty functions are very useful in enabling the solution of constrained problems as unconstrained. The solutions that violate any number of constraints are penalized, which results in associating high objective function values to nonfeasible solutions. Of the two types of penalty functions, stationary (static) function generally exhibit an inferior performance to that of nonstationary 
(dynamic) function. A nonstationary penalty function is generally defined as follows:

$$
f(X)=F(X)+p\left(X, c_{\mathrm{pn}}, e_{\mathrm{pn}}\right),
$$

where $F(X)$ is the original objective function of the constrained optimization problem and $p(\cdot)$ is a dynamically modified penalty, defined as

$$
\begin{aligned}
& p\left(X, c_{\mathrm{pn}}, e_{\mathrm{pn}}\right)=\sum_{1}^{m} C\left(x_{i}, c_{\mathrm{pn}}, e_{\mathrm{pn}}\right), \\
& C\left(x_{i}, c_{\mathrm{pn}}, e_{\mathrm{pn}}\right)= \begin{cases}\left(c_{\mathrm{pn}} r_{i}\right)^{e_{\mathrm{pn}},} & r_{i}>1 \\
0, & r_{i} \leq 1,\end{cases}
\end{aligned}
$$

where $r_{i}$ is the performance criteria of an individual member (often taken as the ratio of utilization to satisfaction of pertinent design code, or the demand-to-capacity ratio, etc.). Figure 3 pictorially lays out the flowchart for the general GADT algorithm as well as the specifics of the domaintrimming subalgorithm. The algorithm starts by generating a randomized set of potential population of "parent" solutions and then sets out to order them based on their fitness. For fit solutions, no actions are necessary at this point, while the unfit solutions are penalized such that their fitness function values will cause them to be eliminated from the pool. After convergence checking is performed (including maximum number of solution iterations), the GA operations are performed in order to create offsprings that carry the favorable traits of the parents. The top 10 most fit solutions are ordered, updated, and saved. Domain-trimming (DM) is performed once the top 100 most fit solutions are collected. In this step, the domains are reduced such that the least fit solutions are eliminated from the pool of feasible solutions. The domain-trimming was carefully executed in order to guarantee survival of the fittest solutions upon GA reinitiation, which utilizes this pool of solutions as the starting population for the next optimization cycle, and so on until convergence is achieved or any of the stopping criteria is reached, for example, maximum number of populations is reached.

While $e_{\mathrm{pn}}$ and $c_{\mathrm{pn}}$ are the penalty exponent and coefficient, respectively, they enable penalizing the optimization objective function value if $r_{i}$ exceeds unity. Both $c_{\mathrm{pn}}$ and $e_{\mathrm{pn}}$ will minimize the probability of unfit solutions reappearing in subsequent generations and trimmed solution domains by penalizing them with proportional severity to their excessive values above unity. In this investigation, several combinations were considered (Figure 4 ) and the used values of the penalty coefficient and exponent are 2 and 2.5, respectively.

\subsection{GADT Verification Example: Cantilever 10-Bar Planar} Truss Structure. The GADT technique is tested against a classical global optimization problem, the Cantilever 10-Bar Planar Truss Structure optimization problem, before using it to solve offshore problems. This 10-dimensional problem has been investigated by many researchers and has been well-established as a challenging optimization benchmark problem. It has a best discovered global minimum as well as multiple local minima.

Figure 5 shows an illustration of the benchmark structure tested. The length $L$ is 360 in $(914.4 \mathrm{~cm})$, the modulus of elasticity is $10,000 \mathrm{ksi}(68,950 \mathrm{MPa})$, and the assumed material density is $0.1 \mathrm{lb} / \mathrm{in}^{3}\left(2767.990 \mathrm{~kg} / \mathrm{m}^{3}\right)$. The member's deflection and stress restrictions are \pm 2.00 in $(5.08 \mathrm{~cm})$ and $\pm 25.0 \mathrm{ksi}(172.375 \mathrm{MPa})$, respectively. Cross-sectional areas for all structural members can assume any values between $0.1 \mathrm{in}^{2}$ and $35 \mathrm{in}^{2}\left(0.6452 \mathrm{~cm}^{2}\right.$ and $\left.225.806 \mathrm{~cm}^{2}\right)$. All members are designed and optimized independently, which could yield in a unique cross-sectional area for each member $\left(A_{1}\right.$ to $\left.A_{10}\right)$. This truss optimization problem has 10 design variables that are subject to 32 constraints (10 compression stresses, 10 tension stresses, and 12 displacements). The studied scenario is when $P_{1}=150$ kips $(667.2 \mathrm{kN})$ and $P_{2}=50$ kips $(222.4 \mathrm{kN})$.

Table 1 gives the best optimum computed solutions with the corresponding minimum weight for the considered scenario, compared against optimal designs presented by scholarly studies available in the literature. Note that it required nearly 4000 iterations to reach the best discovered solution with an initial population size of 500 solutions prior to any domain reductions.

The optimal solutions found by GADT satisfied all the problem constraints and Table 1 demonstrates how GADT's performance is superior to preestablished solutions.

Figure 6 shows the convergence history for the GA and the GADT solutions. The GADT is distinctively outperforming the conventional GA, by converging to more optimal solution in lower number of iterations. Notice that GADT convergence plateaus after approximately 800 iterations after which any trimming has minimal effect on the GA, indicating that most or all unfit values have been eliminated.

\section{Problem Formulation for Offshore Jacket Structure Optimization}

The proposed optimization problem for the supporting wind turbine truss structure is highly sophisticated as it requires the determination of the optimum configuration of geometry, shape, and member sizes simultaneously. The mathematical expression of the problem is as follows:

$$
\begin{aligned}
\text { Find } & A^{T}=\left\{A_{1}, A_{2}, \ldots, A_{n}, x_{s}, y_{s}, z_{s}\right\} \\
\text { To Minimize } & F=W\left(A, x_{s}, y_{s}, z_{s}\right)=\rho \sum_{i=1}^{n} L_{i} A_{i} \\
\text { Subject to } & g_{j}^{L} \leq g_{j}(A) \leq g_{j}^{U} \quad j=1,2, \ldots, m, \\
& A_{i}^{\min } \leq A_{i} \leq A_{i}^{\max } \quad i=1,2, \ldots, n,
\end{aligned}
$$

where $A_{i}$ is the design variable $i$ (member $i$ cross-sectional area), $W(A)$ is the objective function (the structural weight), $\left(x_{s}, y_{s}\right.$, and $\left.z_{s}\right)$ are the members' end nodes coordinates, $\rho$ is the material density, $m$ is the number of inequality constraints $(g), n$ is the number of the design variables, $L_{i}$ is the member length, and $A_{i}^{\max }$ and $A_{i}^{\mathrm{min}}$ are the upper and the lower bounds of the $i$ th variable. Joint displacements and truss 


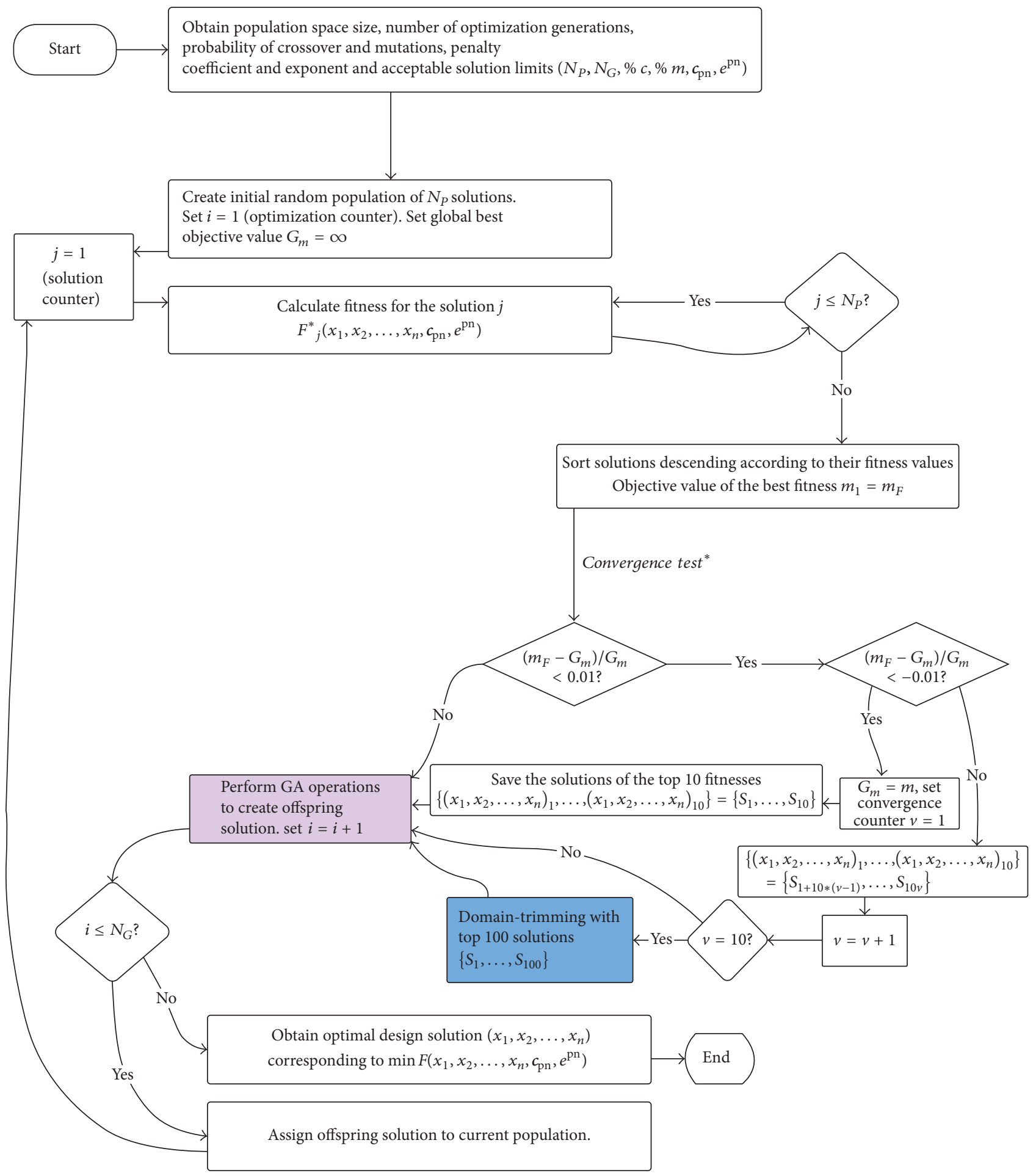

$N_{P}$ : Population size (Number of solutions per iteration)

$\% c$ : Probability of crossover between two solutions

$c_{\text {pn }}:$ Penalty coefficient

$X$ : Vector of design variables

$m_{F}$ : Total mass of the best solution in an iteration
$N_{G}$ : Number of generations (iterations)

$\% m$ : Probability of mutation in one solution

$e^{\text {pn }}$ : Penalty exponent

$F_{j}: \quad$ Fitness function for solution $j$

$G_{m}$ : Total mass of the best solution in all iterations.

(a) Flow chart of general GADT optimization. ${ }^{*}$ Convergence test: if the mass passes both diamonds the top ten solutions of the iteration get saved [until this is repeated 10 times ( $v$ counter) and then domain-trimming happens]. If it passes the first diamond only then the counter is reset. 


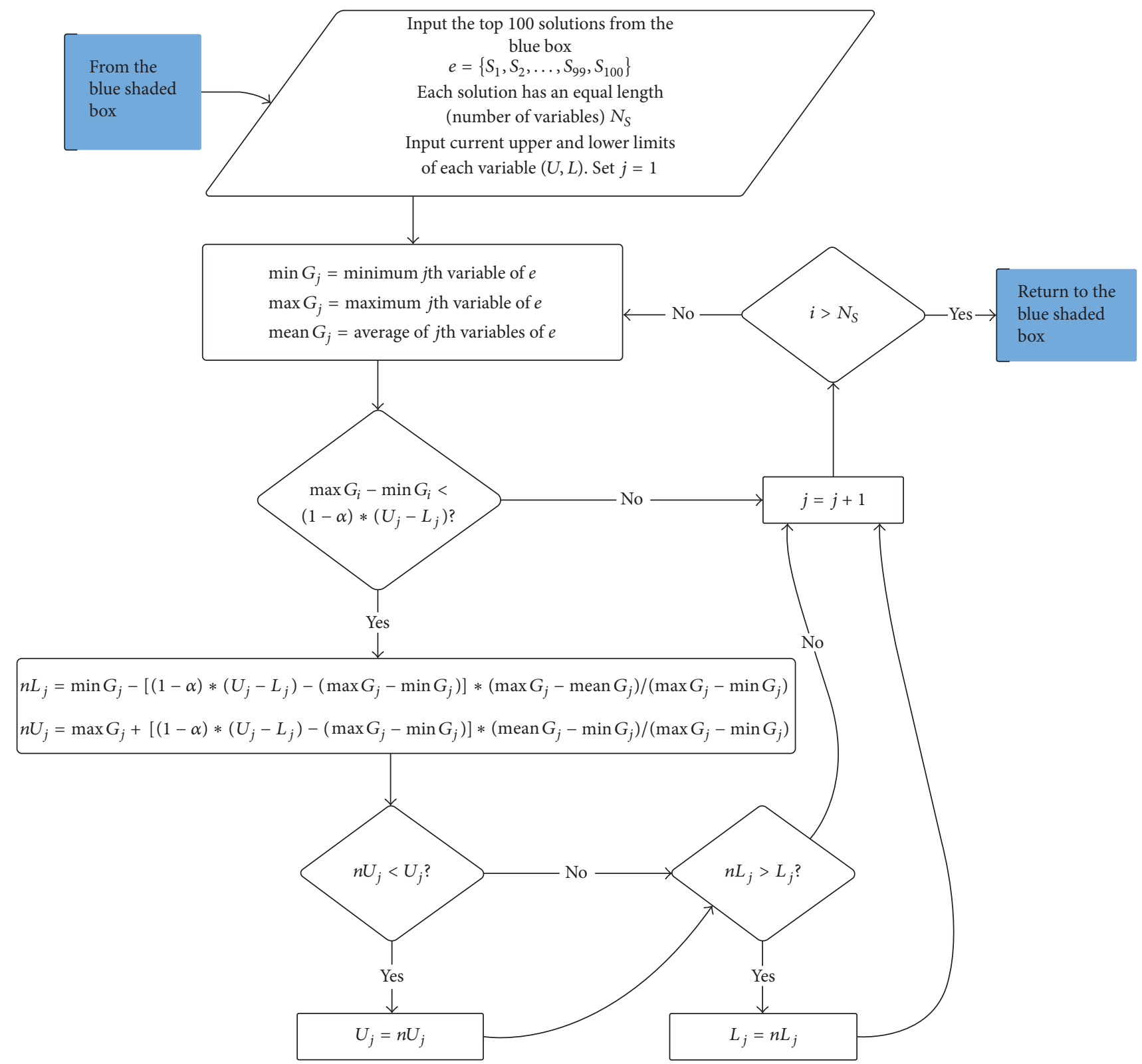

$N_{S}:$ Number of variables in a solution

$L_{j}$ : $\quad$ Lower limit of variable $j$

$n U_{j}$ : New upper limit of variable $j$ $\alpha: \quad$ Reduction percentage of the domain

$U_{j}$ : Upper limit of variable $j$

$n L_{j}$ : New lower limit of variable $j$

(b) Flowchart of domain-trimming

Figure 3

member stresses based on the specified design code constitute the upper and lower bounds of the constraints given in (4).

Combining the penalty and objective functions produces the fitness function used in GADT:

$$
\begin{aligned}
\min & F\left(A_{i}, x_{i}, y_{i}, z_{i}, c_{\mathrm{pn}}, e_{\mathrm{pn}}\right) \\
& =f\left(A_{i}, x_{i}, y_{i}, z_{i}\right)+p\left(A_{i}, x_{i}, y_{i}, z_{i}, c_{\mathrm{pn}}, e_{\mathrm{pn}}\right) .
\end{aligned}
$$

To limit the spatial shapes of structure to practical and feasible potential solutions, joint coordinates are restricted to remain on the main (vertically inclined) legs but are free to move along them (see Figure 7). Thus, the design parameters and their combinations that would be explored are as follows: the slope of the main legs $(S)$, the members' lengths $(L)$, diameters $(D)$, and wall thicknesses (WT). For each spatial configuration combined with members' sizes, the 


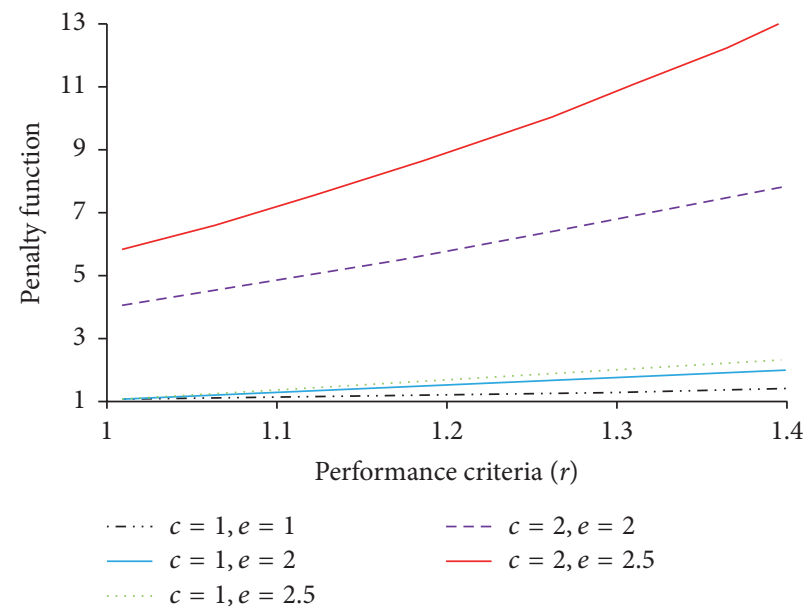

FIGURE 4: Penalty function considered options for eliminating unfeasible solutions; the $(c=2, e=2.5)$ combination was selected.

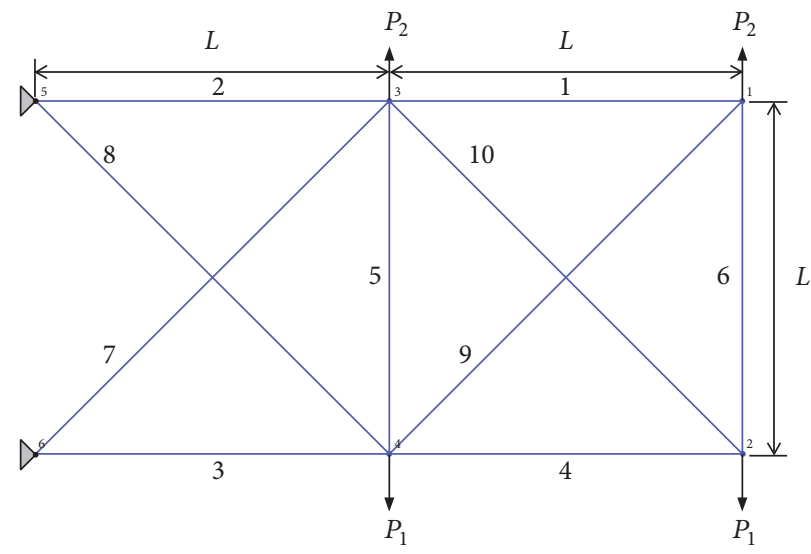

Figure 5: 10-bar planar cantilever truss model.

total structural weight is calculated as the objective function to be minimized.

4.1. Numerical Illustrations. The efficiency of the GADT algorithm is demonstrated through two widely used offshore wind turbine support systems, namely, the quatropod and the tripod jacket trusses (Figure 8). The two design problems are subjected to the offshore loading conditions described earlier. A total mass of $3.4 \times 10^{5} \mathrm{~kg}$ represents the turbine mass assumed to be atop the towers. The supporting truss systems are analyzed for load combinations and designed for conditions specified according to the ASCE7-10 [51] design specifications and the 2010 AISC-LRFD design specifications for steel structures [52].

The design constraints included the traditional permissible member stresses and truss joint displacements prescribed in the adopted AISC-LRFD design standard. All structural elements are modeled as frame elements subjected to gravity as well as wind, wave, and seismic loads. The dead loads are accounted for by the member dimensions and density, while the turbine weight is superimposed at the appropriate location. Typical live loads are treated as movable and temporary, and, as such, a static equivalent uniform $50 \mathrm{psf}(2.39 \mathrm{kPa})$ was used. A typical water depth for the type of jacket was adopted $110 \mathrm{ft}(33.5 \mathrm{~m})$. The wave loading application was carried out via a 5 th-order Stokes theory representation. The design wave was designated as a 100-yr return event with a height of $26 \mathrm{ft}(7.92 \mathrm{~m})$ and the period of $8 \mathrm{sec}$. The horizontal velocity contours for the waves during the 100yr design storm conditions are shown in Figure 9. The $C_{d}$ and $C_{m}$ values are adopted from the recommendations of the API document $[1,2]$ to be 0.65 and 1.6 , respectively. Since the wave loads are represented in a static fashion, the load direction and incidence angle are varied and an envelope of the different scenarios was used for the analysis and design. Specifically, the wave loading was applied in the following configurations: $0^{\circ} / 180^{\circ}, 45^{\circ} / 135^{\circ}$, and $90^{\circ} / 270^{\circ}$. The wind loading was combined with the wave loading due to their close coupling and associations. The design wind speed was chosen to be $100 \mathrm{mph}(45 \mathrm{~m} / \mathrm{s})$ measured at $30 \mathrm{ft}$ (10 $\mathrm{m}$ ) above the Lowest Astronomical Tide (LAT). The wind speed variation with elevation is typically assumed to follow a power law relationship. Equation (6) is used for wind speed evaluations:

$$
V_{Z}=V_{30}\left(\frac{Z}{30}\right)^{X},
$$


TABLE 1: Optimization results for the 10-bar planar truss.

\begin{tabular}{|c|c|c|c|c|c|c|c|}
\hline \multirow[b]{2}{*}{$\begin{array}{l}\text { Variable }\left(\mathrm{in}^{2}\right) \\
\left(\mathrm{cm}^{2}\right)\end{array}$} & \multirow[b]{2}{*}{ This work } & \multicolumn{4}{|c|}{ Optimal cross-sectional areas } & \multirow[b]{2}{*}{ Venkayya [42] } & \multirow[b]{2}{*}{$\begin{array}{c}\text { Dobbs and } \\
\text { Nelson } \\
{[43]}\end{array}$} \\
\hline & & $\begin{array}{c}\text { Kaveh and } \\
\text { Talatahari [38] }\end{array}$ & $\begin{array}{c}\text { Lee and Geem } \\
{[39]}\end{array}$ & $\begin{array}{l}\text { Schmit and } \\
\text { Farshi [40] }\end{array}$ & $\begin{array}{c}\text { Schmit and } \\
\text { Miura [41] }\end{array}$ & & \\
\hline \multirow{2}{*}{$A 1$} & 23.764 & 23.052 & 23.25 & 24.29 & 23.55 & 25.19 & 25.81 \\
\hline & 153.3 & 148.72 & 150.0 & 156.7 & 151.9 & 162.5 & 166.5 \\
\hline \multirow{2}{*}{$A 2$} & 0.101 & 0.1 & 0.102 & 0.1 & 0.1 & 0.363 & 0.1 \\
\hline & 0.652 & 0.645 & 0.658 & 0.645 & 0.645 & 2.342 & 0.645 \\
\hline \multirow{2}{*}{$A 3$} & 25.033 & 25.601 & 25.73 & 23.35 & 25.29 & 25.42 & 27.23 \\
\hline & 161.5 & 165.17 & 166.0 & 150.6 & 163.2 & 164.0 & 175.7 \\
\hline \multirow{2}{*}{$A 4$} & 14.113 & 15.139 & 14.51 & 13.66 & 14.36 & 14.33 & 16.65 \\
\hline & 91.1 & 97.671 & 93.6 & 88.1 & 92.6 & 92.5 & 107.4 \\
\hline \multirow{2}{*}{ A5 } & 0.106 & 0.1 & 0.1 & 0.1 & 0.1 & 0.417 & 0.1 \\
\hline & 0.684 & 0.645 & 0.645 & 0.645 & 0.645 & 2.690 & 0.645 \\
\hline \multirow{2}{*}{ A6 } & 1.987 & 1.969 & 1.977 & 1.969 & 1.97 & 3.144 & 2.024 \\
\hline & 12.8 & 12.703 & 12.8 & 12.7 & 12.7 & 20.3 & 13.1 \\
\hline \multirow{2}{*}{ A7 } & 12.888 & 12.206 & 12.61 & 12.54 & 12.81 & 14.61 & 14.22 \\
\hline & 83.1 & 78.748 & 81.4 & 80.9 & 82.6 & 94.3 & 91.7 \\
\hline \multirow{2}{*}{$A 8$} & 12.427 & 12.568 & 12.21 & 12.67 & 12.39 & 12.08 & 12.78 \\
\hline & 80.2 & 81.084 & 78.8 & 81.7 & 79.9 & 77.9 & 82.5 \\
\hline \multirow{2}{*}{ A9 } & 0.1 & 0.1 & 0.1 & 0.1 & 0.1 & 0.513 & 0.1 \\
\hline & 0.645 & 0.645 & 0.645 & 0.645 & 0.645 & 3.310 & 0.645 \\
\hline \multirow{2}{*}{$A 10$} & 20.253 & 20.33 & 20.36 & 21.97 & 20.34 & 20.26 & 22.14 \\
\hline & 130.7 & 131.16 & 131.4 & 141.7 & 131.2 & 130.7 & 142.8 \\
\hline \multirow{2}{*}{$\begin{array}{l}\text { Weight (Ib) } \\
(N)\end{array}$} & 4668.78 & 4676.05 & 4668.81 & 4691.84 & 4676.96 & 4895.6 & 5059.7 \\
\hline & 20775.6 & 20808.0 & 20775.8 & 20878.3 & 20812.0 & 21785.0 & 22515.2 \\
\hline $\begin{array}{l}\text { Max } \\
\text { deflection }\end{array}$ & 2.00 & 2.00 & 2.00 & 2.00 & 2.00 & 2.00 & 1.82 \\
\hline Max stress & 25.0 & 25.0 & 25.0 & 25.0 & 25.0 & 23.3 & 25.0 \\
\hline
\end{tabular}

where $V_{Z}$ is velocity at height of $Z$ feet (ft/sec); $V_{30}$ is velocity at height of 30 feet (ft/sec); $Z$ is height above LAT (feet); $X=$ $0.125 ; V_{Z}$ shall not be less than $V_{30}$.

Seismic loads were accounted for using the 2006 International Building Code [53] response spectrum constructed based on a 2,500-yr event corresponding to high seismicity. All specifics of the load case definition are in Figure 10. The earthquake loads were also applied in the same directions as the wind and wave loads in order to justify implementing them in load combinations as per the ASCE7-10 [51] design specifications. The ASCE7-10 strength deign load combinations are well-known and not listed herein for brevity.

\section{Results and Discussion}

The GADT algorithm is applied to the structures mentioned above. The effects of the GADT control parameters (population size, penalty coefficient, and exponent) on the optimum solutions are explored and the combination producing the best results is adopted but omitted for brevity.
5.1. Quatropod (64-Bar) Jacket Structure. The truss members are assigned to one of 14 member groups as the 64-bar $3 \mathrm{D}$ truss structure is symmetric about both principal axes ( $X$ and $Y$ ). The 14 groups are as follows: 1 group for the slope of the main legs, 1 group for supports, 1 group for the rod, 1 group for platform beams, 5 groups for bracing members, and 5 groups for legs members. Figure 7 illustrated each of these groups. Therefore, the optimization problem has 33 independent design variables and 32 constraints (6 displacements, 13 tension stresses, and 13 compression stresses). Table 2 gives the best discovered solutions for the 64-bar 3D truss structure.

The GADT algorithm produced an optimum weight of $3,965,364 \mathrm{kgf}$ after completing 500 searches as shown in Figure 11. It is worth mentioning that the optimal solutions found by the GADT meet all constraints and, thus, have no active constraints.

5.2. Tripod (48-Bar) Jacket Structure. Similar to the quatropod jacket, the tripod jacket truss members are assigned to 


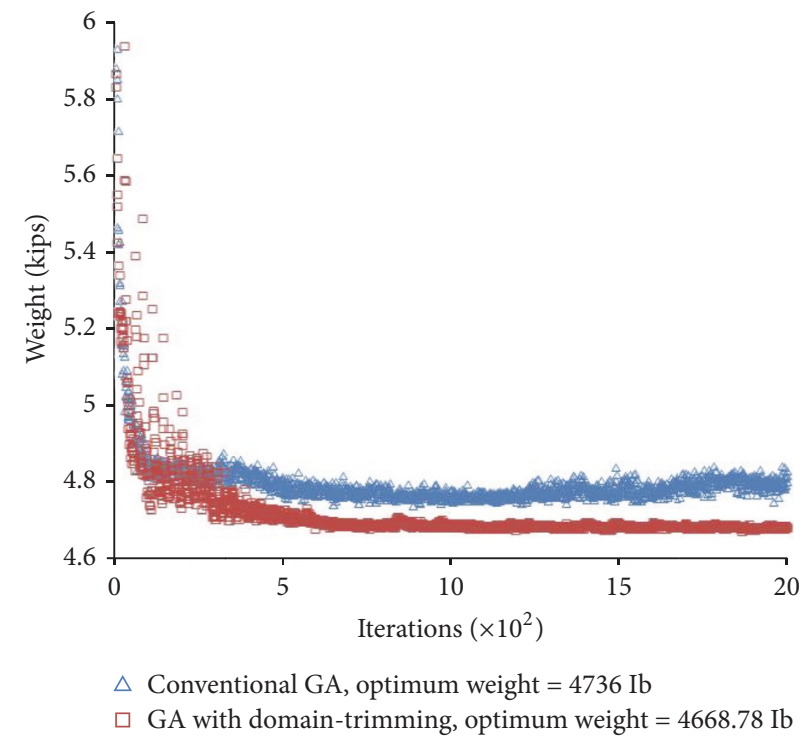

FIGURE 6: Path to optimum solution for the 10-bar planar truss via GA and GADT.

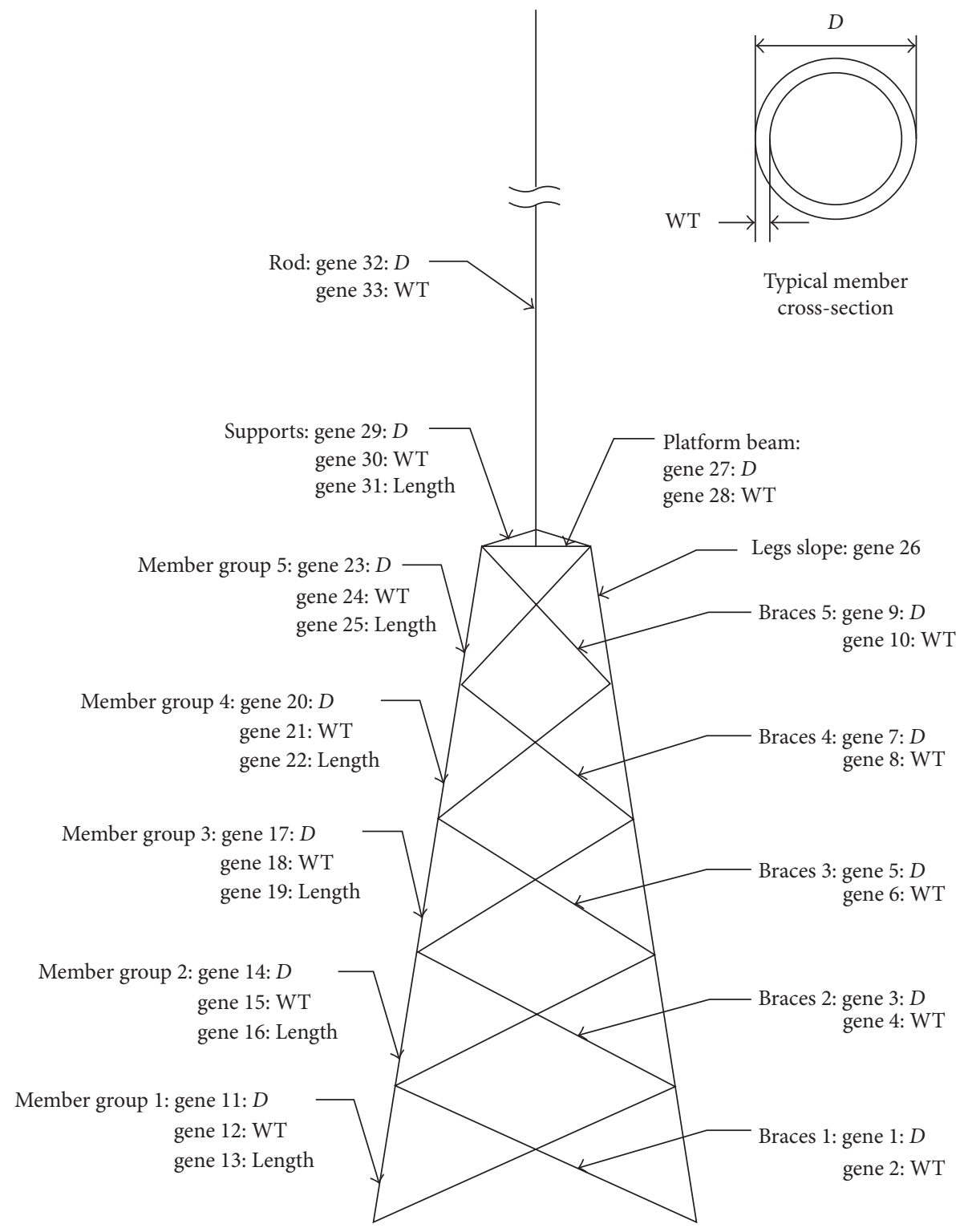

FIGURE 7: Description of the design groups (variables) in optimization problem. 


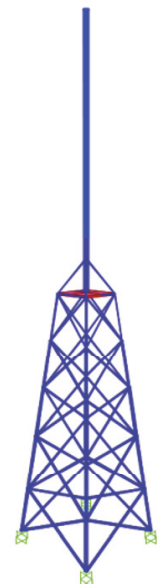

(a)

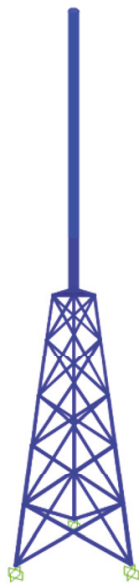

(b)

FIGURE 8: Wind turbine supporting truss structures: (a) quatropod jacket and (b) tripod jacket.

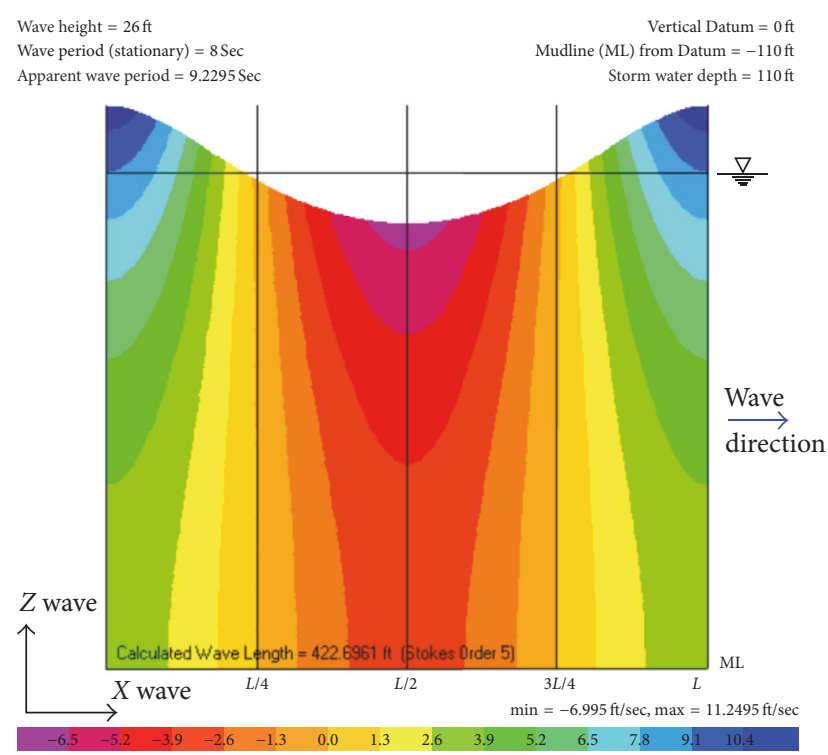

FIGURE 9: Horizontal wave velocity contours for the 100-yr return storm event [37].

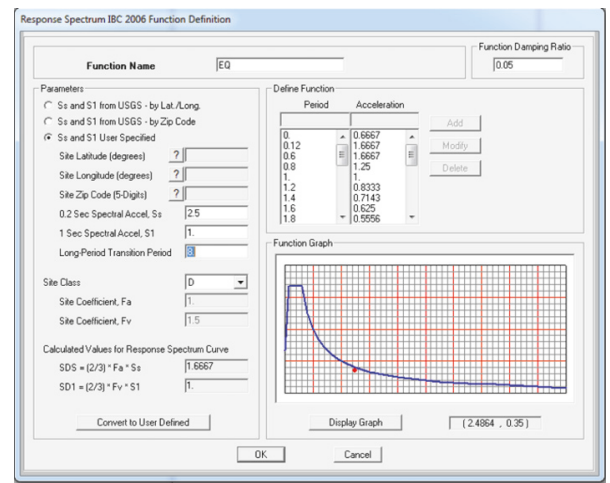

Figure 10: Earthquake load case definition [37].

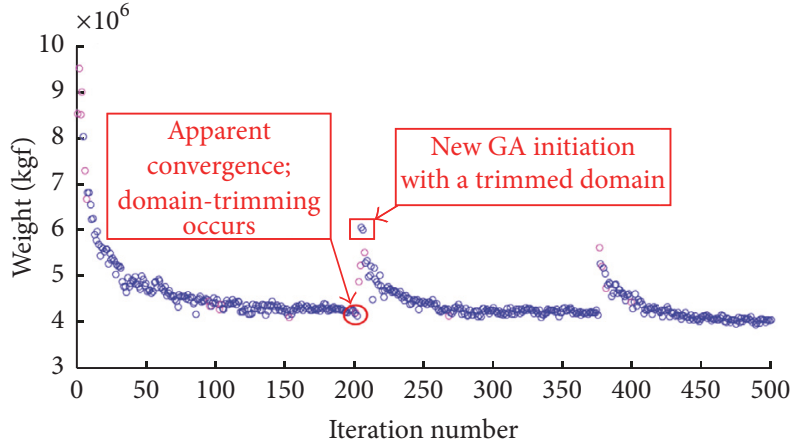

FIGURE 11: Convergence history for the minimum weight of the 64bar 3D truss.

one of the 14 member groups that are illustrated in Figure 7. Again, the optimization problem has 33 independent design variables and 32 constraints. Table 3 gives the best discovered solutions for the 48-bar 3D truss structure.

The GADT algorithm produced an optimum weight of $3,901,710 \mathrm{kgf}$ after completing 1000 searches as shown in Figure 12. Similarly, the optimal solutions found by the GADT meet all constraints, and thus, have no active constraints.

5.3. Computational Efficiency versus Best Discovered Optima. The GADT is observed to outperform the conventional GA technique in terms of discovering optima consistently throughout the three problems presented in this paper. Typically, such improvements to optimal solutions come at a computational price. The domain-trimming and GA reinitiation are the main sources of additional computational cost. However, it can be reported that the GADT is still considered to be a rather computationally efficient technique. In comparison to the conventional GA, the GADT optimization algorithm offers improvements to the discovered optima, which far exceed the minute extra numerical burden. A headto-head performance comparison on the 10-bar benchmark 
TABLE 2: Optimal design values for the 3D 64-bar space truss (quatropod jacket).

\begin{tabular}{|c|c|c|c|c|c|c|c|c|}
\hline \multicolumn{9}{|c|}{ Optimal design variables $(\mathrm{m})$} \\
\hline \multicolumn{2}{|c|}{ Variable } & \multirow{2}{*}{$\frac{\mathrm{BDV}^{*}}{0.74}$} & \multicolumn{2}{|c|}{ Variable } & \multirow{2}{*}{$\begin{array}{r}\text { BDV } \\
0.14\end{array}$} & \multicolumn{2}{|c|}{ Variable } & \multirow{2}{*}{$\frac{B D V}{0.57}$} \\
\hline 1 & $D$ & & 12 & WT & & 23 & $D$ & \\
\hline 2 & WT & 0.055 & 13 & $L$ & 13.53 & 24 & WT & 0.08 \\
\hline 3 & $D$ & 0.71 & 14 & $D$ & 0.96 & 25 & $L$ & 13.50 \\
\hline 4 & WT & 0.047 & 15 & WT & 0.12 & 26 & $S$ & $8.00^{\circ}$ \\
\hline 5 & $D$ & 0.64 & 16 & $L$ & 11.75 & 27 & $D$ & 0.59 \\
\hline 6 & WT & 0.036 & 17 & $D$ & 0.74 & 28 & WT & 0.07 \\
\hline 7 & $D$ & 0.55 & 18 & WT & 0.13 & 29 & $D$ & 0.45 \\
\hline 8 & WT & 0.037 & 19 & $L$ & 13.91 & 30 & WT & 0.07 \\
\hline 9 & $D$ & 0.54 & 20 & $D$ & 0.59 & 31 & $L$ & 5.10 \\
\hline 10 & WT & 0.035 & 21 & WT & 0.12 & 32 & $D$ & 1.80 \\
\hline 11 & $D$ & 0.84 & 22 & $L$ & 9.80 & 33 & WT & 0.06 \\
\hline \multicolumn{2}{|c|}{ Weight (kgf) } & $3,965,364$ & & & $\mathrm{DV}=$ & 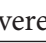 & & \\
\hline
\end{tabular}

TABLE 3: Optimal design values for the 3D 48-bar space truss (tripod jacket).

\begin{tabular}{|c|c|c|c|c|c|c|c|c|}
\hline \multicolumn{9}{|c|}{ Optimal design variables (m) } \\
\hline \multicolumn{2}{|c|}{ Variable } & \multirow{2}{*}{$\frac{\mathrm{BDV}^{*}}{0.73}$} & \multicolumn{2}{|c|}{ Variable } & \multirow{2}{*}{$\frac{\text { BDV }}{0.14}$} & \multicolumn{2}{|c|}{ Variable } & \multirow{2}{*}{$\begin{array}{r}\text { BDV } \\
0.60\end{array}$} \\
\hline 1 & $D$ & & 12 & WT & & 23 & $D$ & \\
\hline 2 & WT & 0.03 & 13 & $L$ & 12.83 & 24 & WT & 0.13 \\
\hline 3 & $D$ & 0.62 & 14 & $D$ & 0.86 & 25 & $L$ & 12.94 \\
\hline 4 & WT & 0.025 & 15 & WT & 0.14 & 26 & $S$ & $9.58^{\circ}$ \\
\hline 5 & $D$ & 0.59 & 16 & $L$ & 13.08 & 27 & $D$ & 0.36 \\
\hline 6 & WT & 0.041 & 17 & $D$ & 0.65 & 28 & WT & 0.08 \\
\hline 7 & $D$ & 0.46 & 18 & WT & 0.14 & 29 & $D$ & 0.40 \\
\hline 8 & WT & 0.032 & 19 & $L$ & 13.55 & 30 & WT & 0.09 \\
\hline 9 & $D$ & 0.55 & 20 & $D$ & 0.61 & 31 & $L$ & 5.27 \\
\hline 10 & WT & 0.061 & 21 & WT & 0.12 & 32 & $D$ & 1.55 \\
\hline 11 & $D$ & 1.06 & 22 & $L$ & 9.94 & 33 & WT & 0.06 \\
\hline \multicolumn{2}{|c|}{ Weight $(k g f)$} & $3,901,710$ & & & $3 \mathrm{DV}=$ & vere & & \\
\hline
\end{tabular}

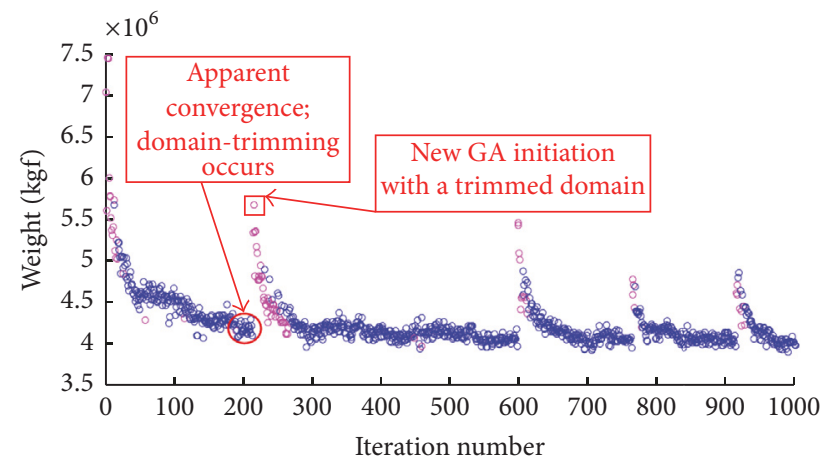

FIGURE 12: Convergence history for the minimum weight of the 48bar 3D truss.

problem demonstrated the superiority of the GADT over conventional GA. A more thorough and conclusive comparison between the GADT versus conventional GA can be included in a future study.

\section{Summary and Conclusions}

The genetic algorithm optimization technique is augmented with a novel "domain-trimming" variation. The resulting superior optimization technique is called Genetic Algorithm with Domain-Trimming (GADT). Initially, the GADT performance is demonstrated by application to the widely used 10-dimensional truss benchmark optimization problem. The 10-bar truss has best discovered global and local minima that are published in the literature. The GADT is shown to be superior to several published solutions. Subsequently, the GADT is deployed onto the main focus of this work, which is three-dimensional structural design optimization for offshore wind turbine supporting structures. This design optimization problem is highly complex entailing leastweight topology and member size optimization. The GADT is applied to two popular alternatives for the offshore wind turbine support structures, namely, quadropod and tripod jacket trusses. This design optimization problem, with its two versions, is nonlinearly constrained where the objective function is the material weight of the supporting truss. The selected 
design variables are the truss members' cross-sectional areas, as well as the truss members' end node coordinates (which determine the members' lengths). The maximum displacements of the nodes and the maximum stresses in members are the applied constraints. These constraints are managed via nonstationary, dynamically modified penalty functions. During analysis and design of the two jacket structures, they are subjected to gravity, wind, wave, and earthquake loading conditions. The results show that the (GADT) method is very efficient in finding the best discovered optimal solutions in both cases. The resulting savings in the optimally designed offshore support structures using the GADT far outweighs the necessary additional computational effort.

\section{Conflicts of Interest}

The authors declare that there are no conflicts of interest regarding the publication of this paper.

\section{References}

[1] American Petroleum Institute-API, "Recommended Practice for Planning, Designing and Constructing Fixed Offshore Platforms-Load Resistance Factor Design, 2A-LRFD (RP 2ALRFD)," 1993.

[2] American Petroleum Institute-API, "Recommended Practice for Planning, Designing and Constructing Fixed Offshore Platforms-Working Stress Design, 2A-WSD (RP 2A-WSD)," 2000.

[3] Det Norske Veritas (DNV), "Result for the Design, Construction and Inspection of Offshore Structures," Oslo, Norway, 1981.

[4] N. Haritos, "Introduction to the analysis and design of offshore structures - an overview," Electronic Journal of Structural Engineering (EJSE), pp. 55-65, 2007.

[5] M. H. AlHamaydeh, S. A. Barakat, and O. M. Nassif, "Optimization of quatropod jacket support structures for offshore wind turbines subject to seismic loads using genetic algorithms," in Proceedings of the 5th ECCOMAS Thematic Conference on Computational Methods in Structural Dynamics and Earthquake Engineering, COMPDYN 2015, pp. 3505-3513, Crete Island, Greece, May 2015.

[6] M. Alhamaydeh and S. Hussain, "Optimized frequency-based foundation design for wind turbine towers utilizing soilstructure interaction," Journal of the Franklin Institute, vol. 348, no. 7, pp. 1470-1487, 2011.

[7] S. Hussain and M. Al Satari, "Vibration-based wind tower foundation design," Wind Systems Magazine, pp. 28-35, 2009.

[8] M. Al Satari and S. Hussain, "Vibration-based wind turbine tower foundation design utilizing soil-foundation-structure interaction," in Proceedings of the 3rd International Conference on Modeling, Simulation and Applied Optimization (ICMSAO’09), pp. 45-53, January 2009.

[9] M. Al Satari and S. Hussain, "Vibration based wind turbine tower foundation design utilizing soil-foundation-structure interaction," in Proceedings of the 2008 Seismic Engineering Conference Commemorating the 1908 Messina and Reggio Calabria Earthquake (MERCEA'08), vol. 1020, p. 577-584, June 2008.

[10] M. Al Satari and S. Hussain, "Vibration based wind turbine tower foundation design utilizing soil-foundation-structure interaction," in Proceedings of the 14th World Conference on Earthquake Engineering (14WCEE), pp. 139-150, October 2008.
[11] W. Dong, T. Moan, and Z. Gao, "Long-term fatigue analysis of multi-planar tubular joints for jacket-type offshore wind turbine in time domain," Engineering Structures, vol. 33, no. 6, pp. 2002-2014, 2011.

[12] M. J. Kühn, Dynamics and Design Optimization of Offshore Wind Energy Conversion Systems, Delft University Wind Energy Research Institute, 2003.

[13] J. Van Der Tempel, Design of Support Structures for Offshore Wind Turbines, Delft University Wind Energy Research Institute, 2006.

[14] N. Alati, V. Nava, G. Failla, F. Arena, and A. Santini, "Fatigue analysis of offshore wind turbines on fixed support structures," Key Engineering Materials, vol. 569-570, pp. 539-546, 2013.

[15] G. N. Vanderplaats, Numerical optimization techniques for engineering design: With Applications, McGraw-Hill Ryerson, Whitby, Canada, 1984.

[16] Q. Y. Duan, V. K. Gupta, and S. Sorooshian, "Shuffled complex evolution approach for effective and efficient global minimization," Journal of Optimization Theory and Applications, vol. 76, no. 3, pp. 501-521, 1993.

[17] N. D. Lagaros, M. Papadrakakis, and G. Kokossalakis, "Structural optimization using evolutionary algorithms," Computers and Structures, vol. 80, no. 7-8, pp. 571-589, 2002.

[18] Q. S. Li, D. K. Liu, A. Y. T. Leung, N. Zhang, and Q. Z. Luo, "A multilevel genetic algorithm for the optimum design of structural control systems," International Journal for Numerical Methods in Engineering, vol. 55, no. 7, pp. 817-834, 2002.

[19] Q. S. Li, D. K. Liu, J. Tang, N. Zhang, and C. M. Tam, "Combinatorial optimal design of number and positions of actuators in actively controlled structures using genetic algorithms," Journal of Sound and Vibration, vol. 270, no. 4-5, pp. 611-624, 2004.

[20] R. J. Balling, R. R. Briggs, and K. Gillman, "Multiple optimum size/shape/topology designs for skeletal structures using a genetic algorithm," Journal of Structural Engineering, vol. 132, no. 7, Article ID 015607QST, pp. 1158-1165, 2006.

[21] R. E. Perez and K. Behdinan, "Particle swarm approach for structural design optimization," Computers and Structures, vol. 85, no. 19-20, pp. 1579-1588, 2007.

[22] G.-C. Luh and C.-Y. Lin, "Structural topology optimization using ant colony optimization algorithm," Applied Soft Computing Journal, vol. 9, no. 4, pp. 1343-1353, 2009.

[23] B. Zhang, Y. Wu, J. Lu, and K.-L. Du, "Evolutionary computation and its applications in neural and fuzzy systems," Applied Computational Intelligence and Soft Computing, vol. 2011, 20 pages, 2011.

[24] M. Kahraman and F. Erbatur, "A GA approach for simultaneous structural optimization," in Proceedings of the Structural Engineering Mechanics and Computation International Conference, pp. 1147-1154, 2001.

[25] H. A. Eschenauer and N. Olhoff, "Topology optimization of continuum structures: a review," Applied Mechanics Reviews, vol. 54, no. 4, pp. 331-389, 2001.

[26] M. P. Bendsoe and O. Sigmund, Topology Optimization: Theory, Method and Application, Springer, Berlin, Germany, 2003.

[27] S. Joncas, M. J. De Ruiter, and F. Van Keulen, "Preliminary design of large wind turbine blades using layout optimization techniques," in Proceedings of the 10th AIAA/ISSMO multidisciplinary analysis and optimization conference, British Columbia, Canada, September 2008.

[28] M. Jureczko, M. Pawlak, and A. Męzyk, "Optimisation of wind turbine blades," Journal of Materials Processing Technology, vol. 167, no. 2-3, pp. 463-471, 2005. 
[29] R. Zakhama, M. M. Abdalla, Z. Gürdal, and H. Smaoui, "Wind load effect in topology optimization problems," Journal of Physics: Conference Series, vol. 75, no. 1, Article ID 012048, 2007.

[30] P. Brøndsted, J. W. Holmes, and B. Sørensen, "Wind rotor blades materials technology," European Sustainable Energy Review, vol. 2, pp. 36-41, 2008.

[31] S. Joncas, Thermoplastic composite wind turbine blades; an integrated design approach, Technische Universiteit Delft, 2010.

[32] L.-C. Forcier and S. Joncas, "New structural design concepts for large thermoplastic wind turbine blades using structural optimization techniques," in Proceedings of the 51st AIAA/ASME/ASCE/AHS/ASC Structures, Structural Dynamics, and Materials Conference, Orlando, Fla, USA, April 2010.

[33] W. Liu and Y. Zhang, "Network study of plant leaf topological pattern and mechanical property and its application," Advances in Natural Science, vol. 3, no. 2, pp. 82-92, 2010.

[34] N. Buckney, A. Pirrera, S. D. Green, and P. M. Weaver, "Structural efficiency of a wind turbine blade," Thin-Walled Structures, vol. 67, pp. 144-154, 2013.

[35] N. Buckney, S. Green, A. Pirrera, and P. M. Weaver, "On the structural topology of wind turbine blades," Wind Energy, vol. 16, no. 4, pp. 545-560, 2013.

[36] "MATLAB Release 2016b." The MathWorks, Inc., Natick, Massachusetts, United States, 2016.

[37] "SAP2000 ver. 18." Computers and Structures, Inc., Berkeley, California, USA, 2016.

[38] A. Kaveh and S. Talatahari, "A hybrid particle swarm and ant colony optimization for design of truss structures," Asian Journal of Civil Engineering (Building and Housing, vol. 9, no. 4, pp. 329-348, 2008.

[39] K. S. Lee and Z. W. Geem, "A new structural optimization method based on the harmony search algorithm," Computers and Structures, vol. 82, no. 9-10, pp. 781-798, 2004.

[40] L. A. Schmit and B. Farshi, "Some Approximation Concepts for Structural Synthesis," AIAA Journal, vol. 12, no. 5, pp. 692-699, 1974.

[41] L. A. Schmit and H. Miura, Approximation concepts for efficient structural synthesis (NASA-CR-2552), NASA, Washington, DC, 1976.

[42] V. B. Venkayya, "Design of optimum structures," Computers Structures, vol. 1, pp. 265-309, 1971.

[43] M. W. Dobbs and R. B. Nelson, "Application of optimality criteria to automated structural designs," AIAA Journal, vol. 14, no. 10, pp. 1436-1443, 1976.

[44] R. G. Dean and R. A. Dalrymple, Water Wave Mechanics for Engineers and Scientists, World Scientific, 1991.

[45] S. K. Chakrabarti, Handbook of Offshore Engineering, vol. I, Elsevier, 2005.

[46] N. Nigam and S. Narayanan, Applications of random vibrations, Springer-Verlag, Berlin, 1994.

[47] S. E. Abdel Raheem, "Nonlinear response of fixed jacket offshore platform under structural and wave loads," Coupled Systems Mechanics, vol. 2, no. 1, pp. 111-126, 2013.

[48] S. Abdel Raheem, E. Abdel Aal, A. Abdel Shafy, and F. Abdel Seed, "Nonlinear Analysis of Offshore Structures under Wave Loadings," in Proceedings of the 15th World Conference on Earthquake Engineering (15WCEE), pp. 366-375, Lisbon, Portugal, 2012.

[49] N. Haritos, "Modelling ocean waves and their effects on offshore structures," in Proceedings of the in Australian Earthquake Engineering Society 2010 Conference, pp. 307-313, 2010.
[50] O. Naseef, Optimization of Natural Rubber Seismic Isolation Systems with Supplemental Viscous Damping for Near-Field Ground Motion, University of Sharjah, Sharjah, United Arab Emirates, 2014.

[51] ASCE 7-10, Minimum Design Loads for Buildings and Other Structures, American Society of Civil Engineers, New York, NY, USA, 2010.

[52] "ANSI/AISC, AISC 360-10: Specification for Structural Steel Buildings, American Institute of Steel Construction, 2010".

[53] International Code Council (ICC), International Building Code - 2006, Falls Church, Virginia, 2006. 


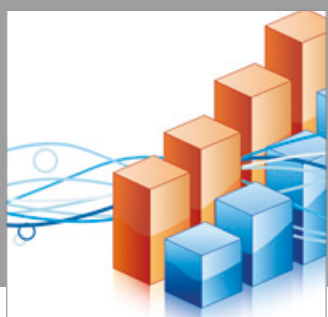

Advances in

Operations Research

vatersals

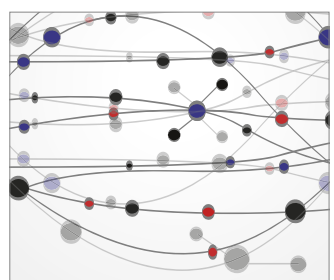

\section{The Scientific} World Journal
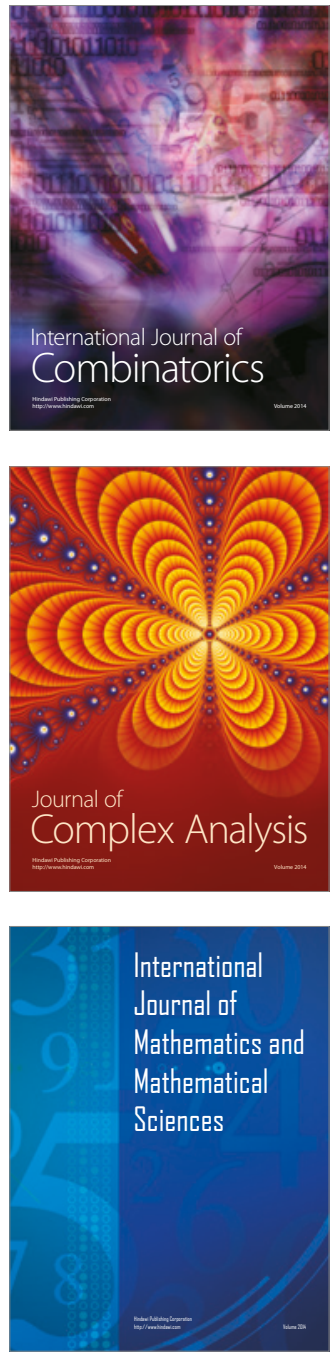
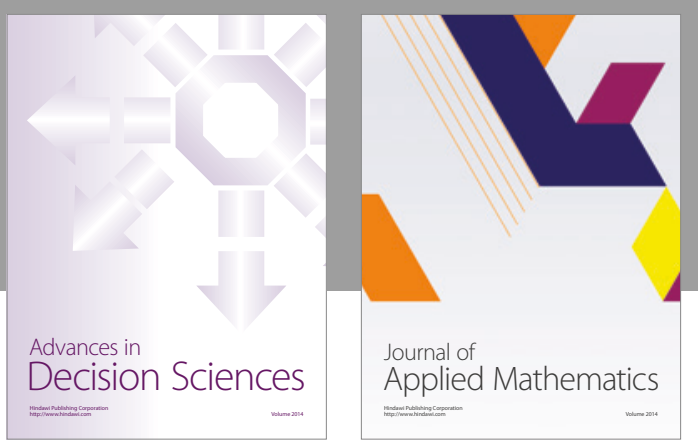

Algebra

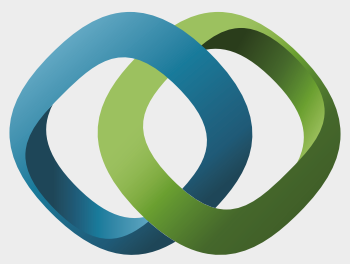

\section{Hindawi}

Submit your manuscripts at

https://www.hindawi.com
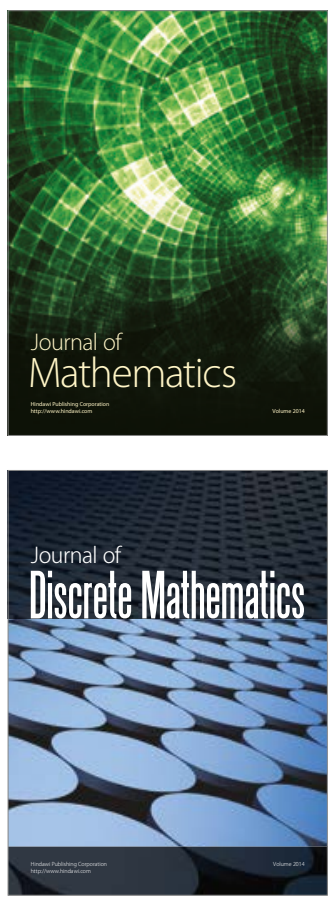

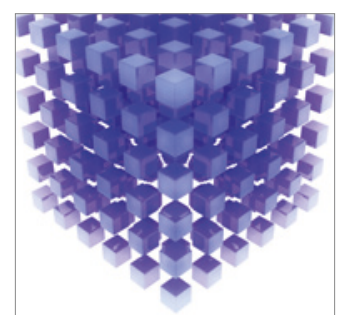

Mathematical Problems in Engineering
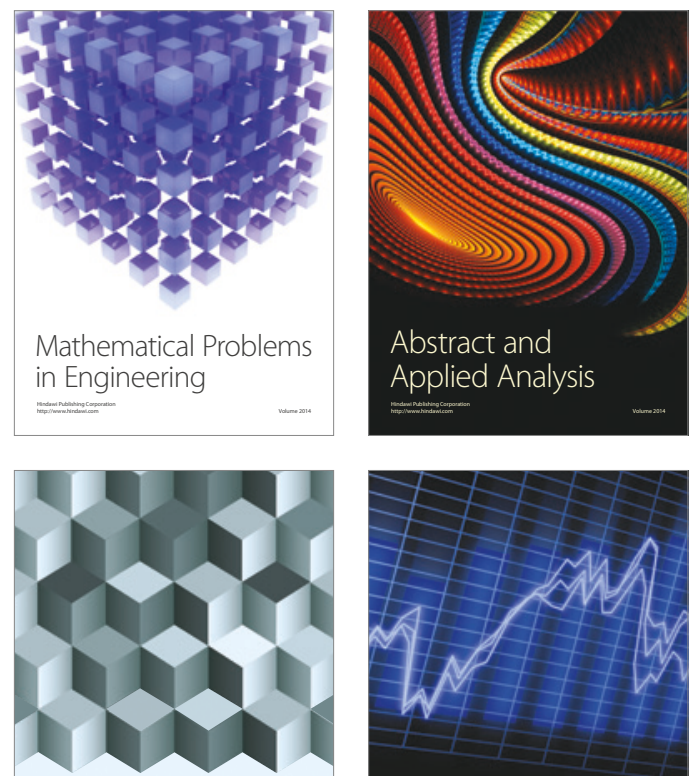

Journal of

Function Spaces

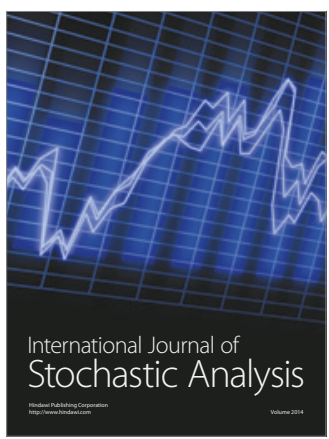

Probability and Statistics
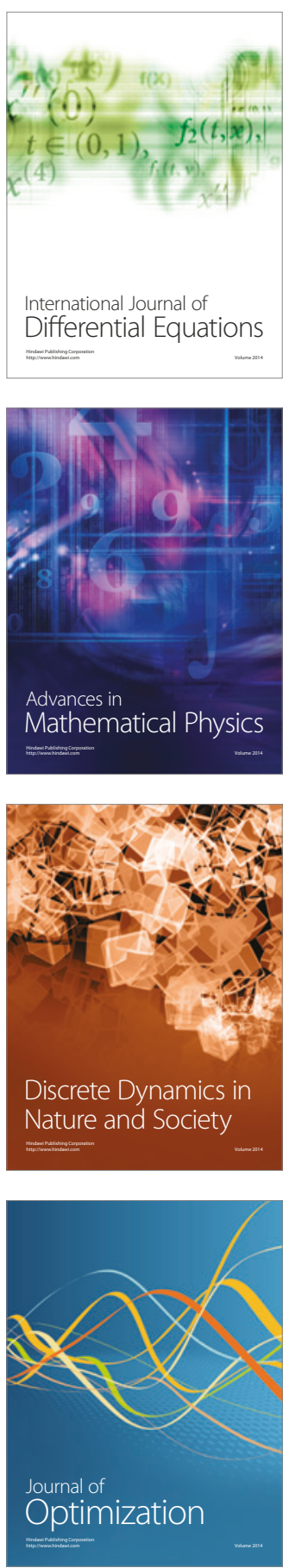